\title{
EXPERIÊNCIAS COM DANÇA NA PESQUISA ACADÊMICA NO SUL DO BRASIL
}

\author{
Sandra Meyer \\ Professora do Programa de Pós-Graduação em Teatro do Centro de Artes em Teatro \\ da Universidade do Estado de Santa Catarina. \\ Doutora em Artes, Comunicação e Semiótica \\ pela Pontifícia Universidade Católica de São Paulo. \\ E-mail: sandrameyer@globo.com
}

\section{Resumo}

Este artigo lança algumas reflexões sobre a pesquisa com dança a partir da corporeidade do artista em contextos universitários. Como tratar da experiência de dançar na pesquisa acadêmica? Questões que emergem da experiência e sua escrita permitem que as universidades problematizem o conhecimento incorporado. Que implicações poéticas, éticas e políticas emergem deste conhecimento?

Palavras-chave

Pesquisa. Experiência. Conhecimento Incorporado. Dança contemporânea.
Abstract

This article presents some reflections about dance research conceived as researching with dance at the context of Brazilian Universities. The involvement of researchers in own dance practices in the university requires epistemological and methodological challenges. How to transform a danced experience in materials for a possible epistemology? Can the artistic processes in dance discuss the notions of truth, ethics, politics and poetics?

Keywords

Research. Experience. Embodied Knowledge. Dance 


\section{Introdução}

Este artigo foi elaborado a partir de uma comunicação intitulada Experiences of dancing on the academic research in Brazil [Experiências de dança na pesquisa acadêmica no Brasil], efetuada na cidade de Atenas, Grécia, em junho de 2015, no Congress on Research in Dance 2015. Apresentei na ocasião algumas reflexões sobre a pesquisa com dança a partir da corporeidade do artista no contexto acadêmico, considerando minha atuação como docente em uma universidade pública brasileira, a Universidade do Estado de Santa Catarina (UDESC). Com o tema "Cut and Paste: Dance Advocacy in the Age of Austerity" [Cortar e colar: a sustentabilidade da dança na época da austeridade] o evento envolveu questões da inserção da dança no contexto socioeconômico atual, oportunizando discutir questões de sustentabilidade e de defesa da dança. $O$ apoio da associação propositora do Congresso, a Society of Dance History Scholars / Congress of Research in Dance (SDHS/CORD) aos colegas da Grécia buscou enfatizar a dança como campo de conhecimento na sociedade e como uma ocupação profissional importante no país, considerando o contexto universitário. ${ }^{1}$ Para tanto, os relatos de experiência de outros países que enfrentam crises e dificuldades puderam contribuir para a construção de um comum: a consolidação da dança como área de conhecimento na Grécia, no Brasil, em todo lugar.

A comunicação estava inserida na mesa-redonda "Dance at Graduate Universities in the

1 SDHS/CORD (Society of Dance History Scholars / Congress of Research in Dance) em colaboração com Hellenic Centre of the International Theatre Institute e Association of Greek Choreographers. Disponível em: http://www.sdhscordconference. org/2015
South of Brazil: experiences and perspectives" [Dança nas instituições de ensino superior no sul do Brasil: experiências e perspectivas], com a participação de outras duas pesquisadoras, Dr. ${ }^{\text {a }}$ Mônica Dantas e Dr. ${ }^{\text {a }}$ Suzanne Weber, ambas docentes do Curso de Dança e de Teatro da Universidade Federal do Rio Grande do Sul (UFRGS) e do Programa de Pós-Graduação em Artes Cênicas da mesma Universidade. A mesa-redonda expôs um panorama do ensino superior em nível de graduação e de pósgraduação em dança no sul do Brasil em duas universidades públicas e gratuitas: UFRGS e UDESC. Estes cursos universitários, nos últimos anos, têm se confrontado cada vez mais com a presença de artistas pesquisadores da dança que buscam investigar seu próprio trabalho ou de outrem.

O Programa de Pós-Graduação em Teatro (PPGT) da UDESC, com mestrado e doutorado implantados, respectivamente, em 2002 e 2009, possui uma linha de pesquisa intitulada Linguagens Cênicas, Corpo e Subjetividade, na qual os estudos em dança estão inseridos. ${ }^{2}$ O PPGT vêm recebendo inúmeros artistas para investigar seu próprio trabalho como performer, o que repercute na maneira com que a experiência de dançar é integrada à pesquisa acadêmica, e isso não se restringe à UDESC. Diante deste quadro, os cursos de pós-graduação de áreas afins vêm abarcando pesquisas de práticas de criação em dança, preenchendo uma lacuna no que se refere à formação em dança no Brasil.

2 O curso de Licenciatura em Teatro, fundado em 1986, tem recebido, desde sua criação, inúmeros artistas da dança ou que se interessaram no decorrer da sua formação pela área, considerando que o curso possui no currículo seis disciplinas voltadas ao corpo e à dança. Desde 2009, o projeto do curso de Licenciatura em Dança elaborado pelo Departamento de Artes Cênicas aguarda repasse de verba do governo para a sua implantação. 
A implicação de pesquisadores em suas próprias práticas de dança no âmbito universitário impõe desafios epistemológicos e metodológicos. Explicitar os saberes implícitos ao ato de dançar permite a visibilidade e a legitimidade do conhecimento que emerge da experiência, deslocando a relação bipartidária entre prática e teoria e suas implicações poéticas, éticas e políticas. Como transformar uma experiência dançada em material para (des)compor possíveis epistemologias? Como os processos criativos em dança problematizam as noções de verdade, universalidade, método e hipótese, tão caros à academia de forma geral?

Reunirei algumas reflexões a partir do contato com artistas pesquisadores da dança, especialmente os vinculados ao PPGT/UDESC. Direciono aqui o entendimento das relações entre corpo e escrita nomeando a pesquisa com dança, aquela que evoca a escrita da própria experiência do artista em processos de criação e formação em salas de aula, de ensaio e outros espaços e situações performativas, diferenciando-a da pesquisa sobre ou em dança, aqui entendida como aquela mais voltada à descrição de outras perspectivas da produção e da recepção da cena. Uma escrita de processo contaminada pelo processo do dançar e que tenta lidar com os conceitos que emergem dos fazeres, propiciando a visibilidade dos seus modos próprios de dizibilidade (Rocha, 2012, p.73). Que implicações emergem do conhecimento "incorporado" propiciado pelo ato de dançar ao ser configurado no e para o ambiente acadêmico? Esta era uma das questões que o Congress on Research in Dance 2015 propunha aos seus participantes.

\section{Pesquisa é} palavra-chave
Antes de adentrar no problema da experiência e do conhecimento em dança na universidade, descrevo brevemente aspectos do ensino superior de dança no Brasil. $^{3}$ A pesquisadora Christine Greiner, no texto "Arte na universidade para germinar questões e testar procedimentos" (2006), alerta para o fato de que, antes dos anos 1980, quando se falava em ensinar dança no Brasil, havia ainda a ideia de que a arte de dançar não se aprenderia em uma instituição universitária. O treinamento técnico que parecia o instrumental necessário e suficiente para dançar estava nas escolas de dança, ateliês e cursos livres e dependia do talento, da vontade, das aptidões inatas e adquiridas.

Nos anos 1990 aumenta a presença de artistas e pesquisadores da dança no ambiente universitário no Brasil, ampliando-se o espaço para a criação e reflexão crítica ${ }^{4}$. O fato de existirem na época poucos cursos de graduação e nenhum mestrado ou doutorado na área de dança, especificamente, contribuiu

3 O primeiro curso de graduação em dança foi implantado em 1956, na Universidade Federal da Bahia, em Salvador, sendo que a proposta não era a de um conservatório de balé, técnica hegemônica de ensino da dança no país na época. Havia um hibridismo da dança de expressão alemã com elementos do candomblé, elaborados por fundadora, a bailarina polonesa Yanka Rudzka (1916-2008), o que evidenciava o tipo de conexão que um curso superior poderia instaurar em relação a outros espaços de circulação de dança no país.

4 Após a criação do primeiro curso, em 1956, na UFBA, somente nos anos 1980 são fundados quatro outros cursos de graduação em dança: da UNICAMP, da UNIVERCIDADE (Rio de Janeiro), do curso da PUC/Paraná - Fundação Teatro Guaíra, atualmente integrando a Faculdade (estadual) de Artes do Paraná (FAP) e da Faculdade Santa Cecília dos Bandeirantes, em Santos, já extinta. Como alerta Cássia Navas (s/d, p.2), este fato coincide com o aparecimento massivo de escolas e academias de ginástica e de dança, e de grandes festivais amadores da década de 1980. Segundo a autora (s/d, p.2): "Num primeiro momento, a criação dos bacharelados em dança surge em descompasso com os rumos da produção do mercado, deixando evidente um não engendramento entre universidade e certas etapas do sistema produtivo da dança, ainda que estas rotas estejam, em alguns casos, sendo sucessivamente corrigidas". 
para a procura de opções por diferentes linhas de pesquisa em contextos interdisciplinares, instaurando interfaces entre arte, filosofia, antropologia, comunicação, semiótica, educação e ciências cognitivas, dentre outras áreas. $A$ dança contemporânea passou a ser entendida como aquela que apresenta um perfil investigativo, ou seja, não se daria somente numa perspectiva de criação de linguagem e seus meios técnicos, mas se utilizaria de referenciais teóricos e conceituais que a legitimasse, alguns próprios (mas não necessariamente) do campo científico e filosófico veiculado nas instituições universitárias.

$\mathrm{Na}$ apresentação da publicação "Coreografia de uma década - O Panorama RIOARTE de Dança" (2001), sobre os dez anos do evento carioca, a pergunta "o que é" dança contemporânea é substituída pelo "desafio de se perguntar: como é a dança contemporânea?" (Pavlova; Pereira, 2001, p.15), considerando o vigor da dança carioca e brasileira na ocasião. A resposta é clara: "Pesquisa é a palavra chave. Aquela que se instaura no corpo. Poder ver no bailarino o que é possibilidade, busca, potencialidade. Poder detectar no corpo o que o mundo fala hoje" (ibidem, p.15). Afirma-se a possibilidade de investigação, por parte do artista, de uma corporeidade própria pelo desvio do passo coreográfico previamente instituído por técnicas de dança codificadas e seus repertórios consolidados, com proposições formativas/poéticas que levem em conta as singularidades que cada corpo possui para entender e ativar dança.

Neste sentido, os cursos superiores de dança no Brasil, cerca de 35 implantados até 2015, têm tido um papel fundamental na elaboração de modos de existência e consolidação de profissionais de dança, possibilitando alternativas de continuidade, diferenciação e diversificação da pesquisa e do ensino da dança. $O$ fato de poder contar com bolsas de pesquisa na universidade se constitui como modo de sobrevivência concreto, aliado ao fato de que muitos destes pesquisadores/artistas não separam teoria e prática na conceituação de seu trabalho, o que torna a universidade um espaço ideal (não o único) para desenvolver suas pesquisas. Lá encontram estrutura para pesquisar e suporte econômico e conceitual pouco disponível em um contexto neoliberal.

\section{Saberes do mover}

Há, na atualidade, em diferentes intuições acadêmicas no país e exterior, um esforço de (re)conhecimento, invenção e registro de modos de pesquisa em dança, abrindo cada vez mais espaço para as práticas e discursos dos artistas, o que implica problematizar, nas próprias instituições, referenciais de investigação do corpo já consolidados. A ideia de que o sistema sensório motor é partícipe da aventura perceptiva e cognitiva inaugura novos entendimentos sobre a relação corpo e mundo. Se concordarmos com a perspectiva do filósofo Alva Noë (2004) ${ }^{5}$ de que o mundo é percebido através do movimento e o que percebemos é determinado pelo que fazemos, talvez os estudos em dança possam oferecer algumas alternativas para repensar modos de conhecer e agir no contexto acadêmico. A dança contemporânea, entendida como modalidade de pensamento e invenção que contém em si a impermanência e a mudança, pode contribuir para repensar dispositivos institucionais tradi-

5 Vale ressaltar que o coreógrafo William Forsythe mantém um diálogo intenso com o filósofo americano Alva Noë que envolve questões cognitivas, filosóficas e poéticas. 
cionais de representação de mundo na academia - hipótese, universalidade, método, verdade -, incluindo a própria ideia de representação em arte.

A pesquisadora e professora da Universidade Paris 8, Isabelle Ginot (2014), no texto Inventer le Metier, aborda os saberes do gesto relacionando-os aos saberes do dançarino. A autora questiona as hierarquias tradicionais entre o conhecimento dominante e o conhecimento minoritário. O que não significa uma alternância de hierarquia, se considerarmos a ideia de que a arte contemporânea não aspira a um conhecimento dominante, pois trairia a sua própria ontologia, mas tratar-se-ia de propiciar fissuras no já estabelecido e inventar outras possibilidades de composição com o real. Ser um pesquisador de dança, para Ginot, implica em uma invenção diária, incluindo a reversão do binarismo teoria e prática. Ela ressalta que é necessário questionar as motivações do pesquisador, em sua dimensão tanto pessoal quanto voltada a uma coletividade, em seus aspectos éticos e políticos. A investigação a que ela se refere com a noção alter-situated research [pesquisa alter-situada] envolve uma invenção de si dentro e fora da universidade, com acadêmicos e não-acadêmicos e orientada para diversos públicos (ibidem, s/p, tradução nossa): "Esta pesquisa alter-situada convida a vigilância no que diz respeito à crescente pressão da normatividade institucional e oferece os estudos de dança como alternativa a esta normatividade"6. Trata-se da pesquisa do corpo, do movimento, do gesto, enfim, do ato de dançar, seja qual for sua lógica, incluindo aquela que se confronta com a ideia de dança

$6[\ldots]$ this alter-situated research invites to vigilance with regards to the ever-increasing pressure of institution normativity, and offers dance studies as alternative to this normativity. como arte suprema do movimento ritmado e coreografado.

Como ressalta Christine Roquet (2011, p.14), também professora da Universidade Paris 8 , diante de razões de toda ordem - éticas, sociais, culturais e políticas - que fundamentariam no ocidente a recusa em valorizar as práticas corporais em detrimento do exercício do logos, "é indispensável para o bailarino, artista do gesto, refletir, falar, nomear seu próprio trabalho", esforço político que ainda tem de ser plenamente reconhecido, pois "trata-se de aprender a 'ler' sobre si mesmo e sobre os diversos modos como um gesto pode se organizar" (Idem, p. 14).

As vozes e os escritos que artistas têm produzido em grande parte não são percebidos, sequer lidos, como se seus processos de criação e de conhecimento em dança pertencessem ao mundo da "prática", dos que "fazem", e não aos que se dedicam a "pensar" a dança ou "falar" sobre ela. Falsa e perversa dicotomia esta. Como nos indaga Gabriele Brandstetter (2012, p.106), professora da Universidade Livre de Berlin: "De onde vem a recusa dessa ideia corporal e performativa do saber, que nos fazer ater às oposições entre teoria e prática, entre racionalidade e emocionalidade, entre mente e corpo?"7. A autora articula um lugar de exposição de um saber diferente - uma "cenagrafia do saber"8, em que a dança deslocaria a fronteira daquilo que tomamos como saber e ciência, "colocando em movimento o nosso

\footnotetext{
7 Estas questões vêm se formulando ao longo do século $X X$ e neste sentido Gabriele Brandstetter chama a atenção para a obra The Thinking Body, publicada por Mabel E. Todd em 1937.

8 No original: Szenographie des Wissens. "Trata-se da ideia de que a dança apresenta uma grafia em cena que expressa um escrita cênica de um conhecimento sobre o humano" (nota de Stephan Baumgartel, tradutor do texto da autora para a Revista Urdimento).
} 
entendimento do próprio saber" (Brandstetter, 2014 p. 106). Pressupostos seguros e a ideia de verdade e de verificabilidade são cada vez mais questionáveis em diferentes campos do conhecimento, o que coloca o saber da arte como alternativa instigante para a existência de outros modos de percepção/invenção de mundo.

Aproximar-se do campo da pesquisa na arte - aqui especificamente com dança a partir da corporeidade do artista/pesquisador - tem sido um dos desafios mais instigantes na atualidade no contexto acadêmico. Não é mais um pesquisador desincorporado. A dimensão incorporada da experiência e o deslocamento das noções de sujeito e de objeto nas práticas contemporâneas em dança despojam identidades e interioridades essencialistas e fixas. A noção de embodiment ${ }^{9}$ nas artes do corpo, a presença a partir da condição de fenômeno temporal corporificado, em continua conexão com o meio, pressupõe a experiência e os desafios de sua compreensão e descrição.

Felizmente as epistemologias e metodologias emergentes de novos cursos universitários de dança no Brasil na atualidade vêm interferindo nos modos de sustentabilidade e profissionalismo em nosso contexto tão amplo e diverso, bem como no entendimento de dança como área de conhecimento, colocando à prova inclusive modelos hegemônicos (aparentemente heterogênicos) de entendimento sobre dança até então vigentes. Diante da perspectiva experiencial da dança no âmbito acadêmico, como o artista pode refletir sobre práticas as quais está implicado? O que significa ter como "objeto" de pesquisa o seu pró-

9 Embodiment fundamenta a premissa de que nossos corpos influenciam a forma como pensamos e que os processos cognitivos estão intrinsecamente conectados ao corpo. prio trabalho? Ou, sendo artista, voltar-se para o fazer de outro artista? Sustenta-se ainda a ideia de distanciamento? Nem demasiada empatia, nem demasiada distância. O equívoco pode estar no significado de distanciamento, especialmente na pesquisa em arte. A distância que devemos investigar, de acordo com o filósofo Bruno Latour, não é entre observador e observado, mas entre a experiência de mundo antes e depois da pesquisa. Portanto, "nem a distância nem a empatia são bons indicadores de que se fez boa ciência; é-o apenas este critério: será que temos, agora, alguma distância entre o novo repertório de ações e aquele com que começamos?" (Latour, 2008, p. 52). Para serem de fato úteis, distância e empatia não podem se esquivar de um critério importante, no sentido de ajudarem, ou não, "a maximizar a ocasião para que o fenômeno em estudo proponha as suas próprias questões, contra as intenções iniciais do investigador" (ibidem, p. 52), por conta de sua implicação com o universo de pesquisa. Trata-se de adotar um tipo de atitude ou de relação encarnada com a pesquisa que revela uma política cognitiva (Kastrup, Tedesco, Passos, 2012). No livro Políticas da Cognição (2015), Virgínia Kastrup, Silvia Tedesco e Eduardo Passos alargam o conceito de cognição ao limite, propondo vetores extracognitivos. A cognição aparece como um processo de produção de subjetividades, onde conhecer, mais do que reconhecer, é inventar.

\section{ideia de teoria como prática}

Para falar de teoria e prática é necessário questionar sua decantada dicotomia, ou seja, ora o predomínio do racional, exaltando a teoria, ora o corporal, exaltando a prática. A ideia 
de co-engendramento (Clareto, 2013, p.150), entre teoria e prática e a noção de experiência são bons antídotos para estas dicotomias. A dança possui boas armas para este enfrentamento, tendo a experiência como aquilo que possibilita a coextensão entre prática e teoria. O conhecimento aqui é entendido como invenção de mundo e não apenas como reconhecimento de um mundo preconcebido.

Sem perceber, enfatizamos o entendimento proveniente da tradição filosófica de que a teoria "ilumina" a prática, numa representação do real (viés idealista), ou que a prática "determina" a teoria (viés materialista), ou numa perspectiva dialética, na qual há uma interação entre elas (Gallo, 2013, p.124). Se buscarmos nos distanciar destas três perspectivas e nos aproximarmos do campo da arte, já não faz sentido as clássicas relações entre teoria e prática. Ao colocar o primado da ação, Deleuze nos permite pensar uma "ação de teoria, ação de prática em relações de revezamento ou em rede" (2006, p. 266). Sendo assim, "a teoria não vai traduzir, expressar ou aplicar uma prática. Ela é uma prática [...]. A teoria é sempre local e regional, e não totalizadora e universal" (p.266, grifo nosso).

"Produz-se teoria e atua-se, trocando os papeis de acordo com a necessidade do momento" (Gallo, 2013, p. 132). A ideia de revezamento entre teoria e prática proposta por Sílvio Gallo, por mais que ataque o problema de forma interessante, ainda reserva certa dicotomia. A proposição de Francisco Varela e Humberto Maturana de que "todo fazer é conhecer e todo conhecer é fazer" (1995, p. $60)$, em seus estudos para o entendimento do processo de conhecimento e da apropriação do saber, pode ser um bom antídoto para o problema, uma vez que a ocorrência do pen- samento e a dimensão conceitual é imanente ao que chamamos de prática, pois todo ato de conhecer produz um mundo. Tal qual o músico que toca as teclas do piano e volta-se para a escrita da partitura para memorizar a recente descoberta, ou o dançarino que observa as linhas de força de seu corpo em pé em contato com o chão e descreve sua experiência ao perceber os acordos que a lei da gravidade lhe imputa. Podemos pensar nas small dances - as micro percepções e ações do corpo na postura ereta imóvel da qual trata Steve Paxton como uma "ação de teoria, ação de prática"?

Numa perspectiva em que pensamento e ação são coexistentes, o pesquisador seria aquele que intervém com a própria prática do pensamento. Neste sentido, teorias passam a ser ferramentas não totalizantes, e sim transitórias e locais, que podem servir ou não para outros contextos. Transitório como o corpo que dança. Esta perspectiva permite uma abertura ao acontecimento, às emergências do corpo e seu ambiente. Neste sentido, a dança na universidade deveria ser o lugar para germinar questões, testar procedimentos, pesquisar práticas, articular reflexões, como aponta o pesquisador francês Hubert Godard (Greiner, 2006 , p. 31). A pesquisa na universidade pode se converter em exercício constante de invenção de práticas conceituais, confrontando-as às já estabelecidas.

Os processos artísticos em dança poderiam ainda contribuir para discutir as noções de método, tão caras à academia? A metodologia define-se por regras previamente estabelecidas, implícitas na própria etimologia da palavra: metá-hódos ${ }^{10}$. Com esse sentido, a pesquisa em geral seria definida como um

10 Metá (reflexão, raciocínio, verdade) + hódos (caminho, direção). (Passos; Barros, 2012, p. 17). 
caminho (hódos) predeterminado por metas a priori. Contudo, a arte é uma das áreas de conhecimento que nos permite transformar o metá-hódos em hódos-metá, ou seja, as metas se organizam no caminhar, numa espécie de cartografia. Essa reversão consiste numa aposta na "experimentação do pensamento um método não para ser aplicado, mas para ser experimentado e assumido como atitude" (Passos, 2009, p.17). Quem experienciou em alguma medida um processo de criação, especificamente em/com dança, sabe que se trata de um (não)saber situacional no espaço/ tempo, afeito a alterações cinestésicas, afetivas, políticas, éticas e poéticas, e que podem propiciar perturbações em campos óbvios do saber.

As produções no espaço ficcional experimental em arte permitem que pensemos em um modo de vida sem sede de verdade, outros mundos, evitando a cristalização que pode levar ao aprisionamento. Cada experiência em dança pode apontar um caminho próprio, que emerge de um (des)saber e um (re)fazer ininterrupto. A precisão e o rigor da pesquisa, contudo, não são descartados e ocorrem como uma intervenção no real.

Referências

BRANDSTETTER, Gabriele. Dança como cena-grafia do saber. Urdimento. Revista de Estudos em Artes Cênicas. Universidade do Estado de Santa Catarina, Florianópolis: vol.1, n. 19, PPGT/UDESC, 2012, p.103-113.
CLARETO, Sonia Maria; OLIVERA, Marta Elaine. Experiência e dobra teoria-prática: a questão da formação de professores. In: CLARETO, Sonia Maria; FERRARI, Anderson. Foucault, Deleuze \& Educação. Juiz de Fora: Editora UFJF, 2013, p. 141-169.

DELEUZE, Gilles. Diferença e Repetição. São Paulo: Editora Graal, 2006.

GALLO, Silvio. Filosofias da diferença e educação: o revezamento entre teoria e prática. In: CLARETO, Sonia Maria; FERRARI, Anderson. Foucault, Deleuze \& Educação. Juiz de Fora: Editora UFJF, 2013, p. 123 -139.

GINOT, Isabelle. Inventer le métier. In: Recherches en danse. 2014. Disponível em: www. danse.revue.org. Acesso em: 15 de março de 2016.

GREINER, Christine. Arte na universidade para germinar questões e testar procedimento. In: MEYER, Sandra; TORRES, Vera; XAVIER, Jussara (Org.) Tubo de Ensaio - Experiências em Arte e Dança Contemporânea. Florianópolis: Edição de autor/UDESC, 2006, p. 31-35

LATOUR, Bruno. Como falar do corpo? A dimensão normativa dos estudos sobre a ciência. In: NUNES, João; ROQUE, Ricardo (Org.). Objectos Impuros: Experiências em Estudos. Porto, Portugal: Edições Afrontamento, 2008.

MATURANA, Humberto; VARELA, Francisco. A árvore do conhecimento: as bases biológicas da compreensão humana. São Paulo: Palas Athena, 1995.

NAVAS, Cássia. A arte da dança na universida- 
de pública contemporânea. Anais da IVa Reunião Cientifica de Pesquisa e Pós-Graduação em Artes Cênicas. s/d. Disponível em: http:// Recebido em: 15/08/2016 www.portalabrace.org/ivreuniao/GTs/pesquiAprovado em: 13/08/2016 sadanca. Acesso em 20 de abril de 2016.

NOË, Alva. Action in perception. Massachusetts: The MIT Press, 2004.

PASSOS, Eduardo; ALVAREZ, Johnny (Org.). Cartografar é habitar um território existencial. Pista n.7. In: PASSOS, Eduardo; KASTRUP, Virgínia; DA ESCÓSSIA, Liliana (Org). Pistas do método de cartografia. Pesquisa-intervenção e produção de subjetividade. Porto Alegre: Editora Sulina, 2009.

KASTRUP, Virgínia; PASSOS, Eduardo; TEDESCO, Silvia (Org). Políticas da Cognição. Porto Alegre: Editora Sulina, 2015.

PAVLOVA, Adriana; PEREIRA, Roberto (Org.). Coreografia de uma década. O Panorama RIOARTE de Dança. Rio de Janeiro: Casa da Palavra, 2001.

ROCHA, Thereza. Dança | filosofia: verso e reverso de um dizer. Urdimento. Revista de Estudos em Artes Cênicas. Universidade do Estado de Santa Catarina, Florianópolis, vol.1, n. 19, PPGT/UDESC, 2012, pp.73-82.

ROQUET, Christine. Da análise do movimento à abordagem sistêmica do gesto expressivo. O Percevejo online, Dossiê Corpo Cênico - linguagens e pedagogias, Rio de Janeiro, vol. 3, n. 1, PPGAC/UNIRIO, 2011, p.01-15. 